\title{
Marco regulador para la regeneración urbana
}

M. ${ }^{a}$ Ángeles González Bustos.

DOI: https://doi.org/10.47623/ivap-rvap.109.2017.1.10

\begin{abstract}
Sumario: I. Regeneración y desarrollo urbano sostenible.-II. La intervención administrativa en materia de regeneración urbana.III. Actuaciones a desarrollar para la regeneración urbana: 1. Actuaciones sobre eficiencia energética en la edificación. 2. Regeneración de barrios o núcleos de población que necesitan de una inmediata intervención. 3. La planificación urbanística.-IV. Conclusiones.
\end{abstract}

\section{Regeneración y desarrollo urbano sostenible}

La expansión del desarrollo urbano, caracterizada en gran parte por la construcción incontrolada de la ciudad, hace que nos encontremos con que en la mayoría de las ciudades el suelo urbano edificable ha llegado a un punto de agotamiento, es decir, de inexistencia de este tipo de suelo para continuar expandiéndose. Unido a esto se producen situaciones de urbanismo desordenado, sin ningún tipo de planificación lo que se traduce en la necesidad de un replanteamiento del urbanismo, o mejor dicho de una regeneración urbana que ha de partir del concepto de desarrollo territorial y urbano sostenible, por lo que la regeneración debe ir unida al desarrollo sostenible, tal y como se señala en el art. 1 del Real Decreto Legislativo 7/2015, de 30 de octubre, por el que se aprueba el del Texto Refundido de la Ley del Suelo y Regeneración Urbana, al establecer como finalidad "el desarrollo sostenible, competitivo y eficiente del medio urbano, mediante el impulso y el fomento de las actuaciones que conducen a la rehabilitación y a la regeneración y renovación de los tejidos urbanos existentes, cuando sean necesarias para asegurar a los ciudadanos una adecuada calidad de vida y la efectividad de su derecho a disfrutar de una vivienda digna y adecuada».

Por desarrollo territorial y urbano sostenible entendemos aquellas políticas públicas que tratan de satisfacer las necesidades urbanísticas de la sociedad actual sin comprometer la posibilidad de las generacio- 
nes futuras de satisfacer las suyas (1). De tal forma que la planificación y ordenación urbanística se consideran como los medios idóneos para ordenar y racionalizar las distintas políticas públicas que inciden sobre el territorio (2).

El problema se plantea en que las formas utilizadas en la explotación y ocupación del territorio han ido en contra del principio de sostenibilidad en sus tres frentes: económico, social y medioambiental; por lo que hay que buscar fórmulas que traten de atenuar lo que se ha venido haciendo hasta el momento en materia de ordenación del territorio ya que resulta prioritario minimizar el impacto del crecimiento urbanístico por medio de la remodelación de la ciudad existente para evitar o reducir los efectos negativos que produce un desarrollo urbano disperso y desordenado.

Es necesario partir de un denominador común como es el suelo(3) considerado tanto desde un punto de vista urbanístico como medioam-

(1) Vid sobre desarrollo sostenible y urbanismo: MARTÍN MATEO, R., "La edificación sostenible», en Revista Aranzadi de Derecho Ambiental, núm. 8, 2005, pp. 15-26; FERNÁNDEZ DE GATTA SÁNCHEZ, D., «Medio Ambiente, urbanismo y edificación: de la política de la Unión Europea al Código técnico de la edificación y a la nueva Ley del suelo", en Revista de Derecho urbanístico, núm. 235, 2007, pp. 26-86; FERNÁNDEZ DE GATTA SÁNCHEZ, D., "Urbanismo y edificación sostenible: su plasmación en el ordenamiento jurídico", en Práctica urbanística, núm. 56, enero 2007, pp. 17-33; FERNÁNDEZ DE GATTA SÁNCHEZ, D., "Articulación y perspectivas del desarrollo sostenible en la Unión Europea», en Noticias de la Unión Europea, núm. 264, 2007, pp. 35 y ss.; GONZÁLEZ PÉREZ, J. (dir.), Comentarios a la Ley del Suelo, Volumen I., 2. ${ }^{\text {a }}$ ed., Thomson-Civitas, Navarra, 2008; IZQUIERDO RONCERO, J.J., "Desarrollo territorial y urbano sostenible: su tratamiento en la legislación española, en Ciudad y Territorio", en Estudios Territoriales núm. 139, 2004, pp. 43-65; LORA-TAMAYO VALLVÉ, M., Derecho urbanístico y Medio ambiente. Hacia el desarrollo urbano sostenible. Dykinson. Madrid, 2004; SÁNCHEZ SÁEZ, A.J., «Elementos jurídicos para la sostenibilidad urbana», en ENTRENA CUESTA, R. (dir), El Derecho urbanístico del siglo XXI. Libro homenaje al profesor Martín Bassols Coma, Tomo II, Ordenación del territorio y urbanismo. Ed. Reus-registradores de España. Madrid. 2008, pp. 575-627; GONZÁLEZ BUSTOS, M. ${ }^{a}$ A., "Desarrollo Territorial y urbano sostenible», en Derecho urbanístico. Guía teórico-práctica. QUINTANA LÓPEZ, T. (dir.). Tirant lo Blanch. Valencia, 2011, pp. 39-49; y de la misma autora: "Desarrollo territorial y urbano sostenible», en FERNANDO PABLO, M.M. (dir) y GONZÁLEZ BUSTOS, M. ${ }^{a}$ A. (coord.), Derecho de la edificación y renovación urbana. Tecnos, 2016, pp. 19-35; CASTILLO BLANCO, F.A (dir), Claves para la sostenibilidad de ciudades y territorios. Thomson Reuters, Aranzadi, 2014...

(2) PÉREZ ANDRÉS: "La ordenación del territorio, una encrucijada de competencias planificadoras", en Revista de Administración Pública, núm. 147, 1998, pp. 98-99. En la misma línea RAMALLO LÓPEZ, F., op. cit. pp. 430-438: BASSOLS COMA, M., «La planificación urbanística y su contribución al desarroIlo urbanístico sostenible", en ESTEVE PARDO, J. (coord.), Derecho del medio ambiente y administración local. Fundación democracia y gobierno local. Barcelona, 2 ed. , 2006; PONCE SOLÉ, J., «Desarrollo territorial y urbanístico sostenible y buena administración mediante la actividad de planificación en la Ley 8/2007. de 28 de mayo, de suelo", en ENTRENA CUESTA (dir), El Derecho urbanístico del siglo XXI. Libro homenaje al Profesor Martín Bassols Coma, Tomo II, Ordenación del Territorio y Urbanismo. Ed. Reus,-Registradores de España, Madrid, 2008, pp. 487-548...Y en general sobre la planificación MARTíN-RETORTILLO, S., Derecho Administrativo Económico II. La ley, 2001, pp. 327-414.

(3) El suelo constituye un recurso ambiental y por lo tanto ha de ser protegido por los medios que pone a disposición el Derecho medioambiental al igual que se protege el resto de los recursos naturales. El suelo es un elemento necesario para el desarrollo de la vida, como puede ser el aire o el agua ya que cumple el mismo objetivo y función; pero además es un recurso finito, y lo que lo diferencia de los demás recursos es su condición de apropiación privada. Esta condición ha hecho que cuando el suelo presta funciones unidas a la actividad del hombre se regulara por el derecho urbanístico. 
biental (4) ya que sólo así es posible dar respuestas a preguntas relativas al modo de vida de los ciudadanos, las condiciones para el desarrollo de las diferentes actividades cotidianas o empresariales, los modelos de planeamiento para la configuración de una ciudad sostenible, la forma de participación de los ciudadanos, empresas, asociaciones... para transformar el modelo de ciudad, etc..

Para hacer frente a los riesgos que se desprenden de un desarrollo incontrolado es conveniente articular medidas destinadas a promover el consumo y la producción sostenible, impulsar la eficiencia ambiental en la industria o en la edificación, utilizar fuentes energéticas renovables, o mejorar el metabolismo ecológico de las ciudades... Lo que nos Ileva a la necesidad de que para conseguir el objetivo de sostenibilidad se deban aprobar y desarrollar políticas públicas dirigidas a dicha finalidad y que den como resultado una regeneración del espacio urbano.

Los primeros documentos relacionados con la materia los encontramos a nivel Europeo a partir del "Libro Verde del Medio Ambiente" (COM (90) 218 final, 26 de julio de 1990) que realiza una descripción completa y establece los retos del mismo para el futuro. A dicha iniciativa le sigue la "Carta de Ciudades Europeas Sostenibles" adaptada en la Conferencia de Aalborg en 1994 en la que se incide sobre los temas ambientales de las ciudades y se incluye el compromiso de elaboración de Agendas 21. Ideas que se plasman en el Plan de Acción de Lisboa aprobado el 8 de octubre de 1996 y en el "Informe sobre las Ciudades Sostenibles" de ese mismo año, reiterándose en junio de 2004, en Dinamarca en la denominada "Conferencia Aalborg+10".

El documento clave ha sido la Estrategia Territorial Europea, de la Comisión Europea 1999, donde se señalan las características fundamentales que deben ser tenidas en cuenta para lograr ese desarrollo sostenible:

- control de la expansión urbana,

- mezcla de funciones y grupos sociales,

- gestión inteligente y economizadora de los recursos del ecosistema urbano (en particular, el agua, la energía y los residuos),

- mejor accesibilidad, gracias a medios de transporte que sean no sólo eficaces sino también compatibles con el medio ambiente, y

- protección y el desarrollo del patrimonio natural y cultural.

Posteriormente, la Comunicación aprobada por la Comisión «Hacia una Estrategia Temática sobre el Medio Ambiente Urbano" (COM (2004) 60 final, 11 de febrero de 2004), realiza un análisis de la situación urbana, y se centra en los siguientes aspectos: la gestión urbana sostenible, el trans-

(4) EITC identifica el suelo como recurso ambiental (STC 102/1995, de 26 de junio). 
porte urbano sostenible, en la construcción sostenible y en el urbanismo sostenible. Se propone que los Estados miembros elaboren sus propias Estrategias Nacionales, así como estrategias regionales que tengan en cuenta los ámbitos locales de actuación. A dicha Comunicación le sigue la Comunicación sobre «Una Estrategia Temática para el Medio Ambiente Urbano" (COM (2005) 718 final, 11 de enero de 2006) en la que se destaca la importancia de las ciudades en la Unión Europea, los retos ambientales (calidad del aire, circulación de vehículos, congestión de circulación y actividades, ruido, construcción de mala calidad, crecimiento urbano desordenado, residuos o aguas), y las causas (cambios en las formas de vida social, cambios demográficos y movilidad, nivel de vida, ...).

Como resultado de la cooperación y colaboración entre los Estados miembros de la Unión Europea, en materia de desarrollo urbano se han aprobado dos documentos claves: la Carta de Leipzig de 2007 (5) y la Declaración de Toledo de 22 de junio de 2010. Estos documentos contienen acuerdos explícitos a nivel europeo sobre el carácter de la ciudad europea del futuro y los principios en los que debe basarse. Existe también consenso a nivel europeo sobre el papel fundamental que pueden desempeñar las ciudades en la aplicación de la Estrategia Europa 2020 relativa al crecimiento de la Unión Europea para la próxima década cuya finalidad es la superación de la crisis económica, y crear las condiciones necesarias para un crecimiento inteligente, sostenible e integrador.

De conformidad con el documento "Ciudades del mañana»(6) en el que se sintetizan los principios del modelo europeo de desarrollo urbano sostenible (7), las ciudades europeas deben ser:

- lugares de progreso social avanzado,

- plataformas para la democracia, el diálogo cultural y la diversidad,

- lugares de regeneración verde, ecológica o medioambiental, y

- lugares de atracción y motores de crecimiento económico.

Por lo que el desarrollo territorial urbano europeo debe:

- reflejar un desarrollo sostenible de Europa basado en el crecimiento económico y la organización territorial equilibrados con una estructura urbana policéntrica.

(5) Vid. sobre la misma MOLINA DEL POZO, C.Fr., "La preocupación de la Unión Europea par lograr ciudades sostenibles: la Carta de Leipzig", en ENTRENA CUESTA, R. (dir), El Derecho urbanístico del siglo XXI. Libro homenaje al profesor Martín Bassols Coma, Tomo II, Ordenación del territorio y urbanismo. Ed. Reus-registradores de España. Madrid, 2008, pp. 429-444.

(6) http://ec.europa.eu/regional_policy/archive/conferences/citiesoftomorrow/index_en.cfm

(7) Basándose en el Tratado de Funcionamiento de la Unión Europea, la Carta de los Derechos Fundamentales de la Unión Europea, el modelo actual europeo, la Carta de Leipzig, la declaración deToledo y la Agenda Territorial 2020. 
- contener centros regionales fuertes que faciliten el acceso a los servicios de interés económico general,

- caracterizarse por una estructura de asentamiento compacta con una exposición urbana limitada, y

- gozar de un elevado nivel de protección y calidad medioambiental en torno a las ciudades.

La necesidad de una agenda urbana para la UE en la que se plasmen el papel de las ciudades europeas como lugares de integración social y cultural así como fuente de desarrollo sostenible es esencial para que todas las políticas nacionales adopten los objetivos y estrategias globales de la UE para lo cual el Comité de las Regiones a finales del 2013 formuló el dictamen "hacia una agenda urbana integrada para la UE», dicho documento es clave para el desarrollo de las estrategias urbanas nacionales.

Siguiendo esta línea de actuación, en España se elaboró la Estrategia Española de Medio Ambiente Urbano de 16 de junio de 2006, que traslada al Derecho español la Estrategia Temática Europea de Medio Ambiente Urbano, y que apunta directrices para el ámbito urbanístico; así como la Estrategia Española de Desarrollo Sostenible aprobada por el Consejo de Ministros el 23 de noviembre del 2007, que tiene como principal objetivo el de promover un desarrollo territorial y urbano sostenible y equilibrado, incentivando, en particular, el desarrollo sostenible en el medio rural. Y finalmente la Estrategia Española de Sostenibilidad Urbana y Local, el 17 de junio del 2011, que establece una serie de ámbitos y áreas temáticas en las que se ha de actuar destacando el punto de vista territorial y urbano; los instrumentos urbanísticos; las cuestiones relacionadas con la accesibilidad, movilidad y transporte; la gestión y la gobernanza urbana; la edificación y la rehabilitación; y el cambio climático (8).

Esto ha llevado a que Comunidades Autónomas y Entidades Locales hayan comenzado a elaborar estrategias de sostenibilidad y las denominadas Agendas 21 (9).

(8) https://www.fomento.gob.es/MFOM/LANG_CASTELLANO/DIRECCIONES_GENERALES/ARQ_VIVIENDA/SUELO_Y_POLITICAS/SOTENIBILIDAD/EESUL/

(9) "Agendas 21 » es una expresión acuñada en la Cumbre de Río 1992 como referencia al Plan de acción que los Estados deben desarrollar para llegar a transformar el modelo de desarrollo actual, basado en la explotación de los recursos naturales como si fueran ilimitados, en un modelo que satisfaga las necesidades de las generaciones actuales sin comprometer la capacidad de las generaciones futuras, es decir por un modelo de desarrollo duradero en el tiempo, eficiente y racional en el uso de los recursos y equitativo en los beneficios, siendo fundamental en el mismo el papel de las ciudades. Lo que nos lleva a señalar que las entidades locales se configuran como un factor decisivo en el desarrollo sostenible aprobando la mayoría de ellas "Las Agendas 21 Locales". 
Es de mencionar, por la influencia que ha supuesto para la aprobación de todas las políticas y programas relacionados con el desarrollos territorial y urbano sostenible, y por consiguiente en todas las actuaciones que se realizan en materia de regeneración urbana, la Directiva 85/377/CEE, del Consejo, de 27 de junio de 1985, relativa a la evaluación de las repercusiones ambientales de determinados proyectos públicos y privados sobre el medio ambiente, y que se traspone en nuestro ordenamiento jurídico a través del Real Decreto legislativo 1302/1986, de 28 de julio, de Evaluación de Impacto Ambiental, modificada por la Ley 6/2001, de 8 de mayo, y posteriormente por la Ley 21/2013, de Evaluación Ambiental (10) . Se introduce así la variable ambiental en la toma de decisiones sobre actuaciones que inciden sobre el medio natural y en todo proceso de edificabilidad(11).

La disposición normativa decisiva a nivel estatal ha sido el RD Legislativo $2 / 2008$, de 20 de junio, por el que se aprueba el Texto Refundido de la Ley del Suelo (TRLS) que establece la necesidad de que el urbanismo responda a las exigencias de un desarrollo sostenible, de tal forma que las políticas públicas relativas a la regulación, ordenación, ocupación, transformación y uso del suelo, tanto autonómicas como municipales, tengan en común la utilización de dicho recurso naturales conforme al interés general (artículo 2 TRLS(12)), posteriormente derogado por vigente Real Decreto legislativo $7 / 2015$, de 30 de octubre, por el que se aprueba el texto refundido de la Ley del Suelo y Rehabilitación Urbana.

El principio de desarrollo sostenible lleva a que todas las políticas deban estar dirigidas a la consecución de un uso más racional de los recursos naturales armonizando los requerimientos de la economía, el empleo, la cohesión social, la igualdad de trato y de oportunidades, la salud y seguridad de las personas y la protección del medio ambiente, contribuyendo en particular a (art. 2TRLSy RU):

a) La eficacia de las medidas de conservación y mejora de la naturaleza, la flora y la fauna y de la protección del patrimonio cultural y del paisaje.

(10) La Generalitat de Cataluña ha interpuesto recurso de inconstitucionalidad contra diversos preceptos de la ley por vulneración del sistema de distribución competencial: STC 53/2017, de 11 de mayo (BOE 15 de junio) que anula determinados preceptos que exceden del ámbito de lo básico y reinterpreta otros.

(11) Vid. sobre la importancia de la Evaluación de Impacto Ambiental y la Evaluación Ambiental en materia de desarrollo urbano sostenible: Arenas Cabello, Fr.J.: op cit., pp. 124-129.

(12) Modificado por la Ley 8/2013, de 26 de junio, de rehabilitación, regeneración y renovación urbana. Este precepto fue impugnado ante el Tribunal Constitucional por considerar que invadía el ámbito competencias de las Comunidades Autónomas, sin embargo, el TC en la Sentencia 11 de septiembre de 2014, ha declarado la constitucionalidad del mismo. 
b) La protección, adecuada a su carácter, del medio rural y la preservación de los valores del suelo innecesario o inidóneo para atender las necesidades de transformación urbanística.

c) La prevención adecuada de riesgos y peligros para la seguridad y la salud públicas y la eliminación efectiva de las perturbaciones de ambas.

d) La prevención y minimización, en la mayor medida posible, de la contaminación del aire, el agua, el suelo y el subsuelo.

Incidiendo a continuación, art. 3.3 TRLSyRU en el medio urbano en donde las políticas se formularán y desarrollarán de acuerdo con los principios de competitividad y sostenibilidad económica, social y medioambiental, cohesión territorial, eficiencia energética y complejidad funcional, procurando que, esté suficientemente dotado, y que el suelo se ocupe de manera eficiente, combinando los usos de forma racional.

Se establecen los principales aspectos que deben ser tenidos en cuenta tales como el uso residencial en un contexto urbano seguro, salubre, accesible y de calidad, la rehabilitación y la ocupación de viviendas vacías o en desuso, la mejora de la calidad y funcionalidad de las dotaciones, infraestructuras y espacios públicos, la movilidad sostenible, mejora de la eficiencia en el uso de los recursos, se priorizará las energías renovables frente a las fuentes de energía fósil, puesta en valor del patrimonio urbanizado y edificado con valor cultural o histórico, ... (art. 3.3TRLSYRU).

Como se puede observar la preocupación por el desarrollo sostenible es una constante en las políticas públicas urbanísticas, culminando con elTRLSyRU que ha supuesto el cambio definitivo del urbanismo hacia una mejora de la ciudad existente, unida a la regeneración de la ciudad, que hace preciso que se preste atención a varios focos como los cascos histórico donde podemos encontrar edificios que precisan de una intervención inmediata, ya que muchos de estos inmuebles se encuentran en una situación de ruina, debido al escaso interés que no en pocos casos demuestran los propietarios (la mayoría ellos herederos) o la inexistencia de recursos económicos de lo que se dispone; los barrios construidos en las décadas de los 60 y 70 necesitan acometidas en las estructuras, unido a que muchos de ellos se han convertido en barrios marginales; así como en la mejora de la eficiencia energética de los edificios existente.

Esto hace indispensable que se actúe de manera urgente buscando modelos basados en la regeneración y rejuvenecimiento de la ciudad, apostando por la reutilización de espacios abandonados, la transformación de las edificaciones antiguas (viviendas, mercados, fábricas...), la 
modernización de infraestructuras portuarias, estaciones de ferrocarriles o la renovación de elementos urbanísticos(13).

\section{La intervención administrativa en materia de regeneración urbana}

Cuando hablamos de regeneración urbana nos referimos a intervenciones sobre suelo urbano ya transformado, por lo que el objeto de la regeneración urbana no es otro que la búsqueda de mecanismos que supongan un freno al deterioro de las áreas urbanas mediante el desarrollo y la mejora de las mismas, así como la solución de los problemas urbanos que presenta un área determinada para que los habitantes y usuarios de la misma disfruten de unos servicios de calidad acordes con el desarrollo sostenible(14).

El término de Regeneración urbana parte de la Carta de Leipzig sobre Ciudades Europeas Sostenibles del 2007 donde, como hemos señalado, se marcan las directrices para el desarrollo sostenible de las ciudades de la UE, definiéndola como "el requisito para alcanzar la sostenibilidad urbana, mejorar el medio ambiente físico de las zonas urbanas desfavorecidas, fortalecer la economía local y la política laboral local, la educación y el transporte». En la misma línea la Declaración de Toledo de 22 de junio de 2010, la define como la «consecución de un desarrollo urbano más inteligente, sostenible y socialmente inclusivo".

(13) Vid. en general sobre rehabilitación, regeneración y renovación urbana: ALONSO IBÁÑEZ, M. ${ }^{a}$ R., "Las actuaciones de regeneración y renovación urbanas", en Práctica Urbanística, núm. 138, 2016, pp. 42-55; FARIÑA TOJO, J., "Ciudad sostenible, rehabilitación arquitectónica y regeneración urbana", en Revista Aragonesa de Administración Públicas, monografías, 2013, pp. 15-26; Fernández de Gatta, D., "Rehabilitación, regeneración y renovación urbanas. Planificación y gestión», en Revista jurídica de Castilla y León, núm. 39, 2016, pp. 1-50; y del mismos autor: "conservación de edificios y construcciones, rehabilitación y renovación urbanas", en FERNANDO PABLO, M.M. (dir) y GONZÁLEZ BUSTOS, M. ${ }^{a}$ A., (coord.).: Derecho de la edificación y renovación urbana, Tecnos, 2016, pp. 307-329; FERNÁNDEZ ACEVEDO, R., "Instrumentos y técnicas urbanísticas para la rehabilitación, regeneración y renovación urbanas", en QUINTANA LÓPEZ, T., (dir.): Urbanismos Sostenible. Rehabilitación, regeneración y renovación urbanas, Ed. Tirant lo Blanch, 2016, pp. 173-216; FERNANDO PABLO, M. (dir.) y GONZÁLEZ BUSTOS, M. ${ }^{a}$ A.: (coord.), Derecho de la Edificación y Renovación Urbana, Tecnos, 2016; FERNÁNDEZTORRES, JR., "La rehabilitación, regeneración y renovación urbana: contexto y desafíos a propósitos de la Ley 8/2013, de 26 de junio", en Revista de Urbanismo y Edificación, núm. 30, 2014, pp. 15-38; GÓMEZ JIMÉNEZ, M. ${ }^{a}$ L., "Informe sobre la regeneración urbana en España: nuevos instrumentos normativos en un escenario de cambios", en Revista de Derecho urbanístico y Medio Ambiente, núm. 285, 2013, pp. 157-188; HERVÁS MÁS, J.: Nuevo régimen jurídico de la regeneración urbana. Thomson Reuters Aranzadi, 2017; QUINTANA LÓPEZ, T., "De la conservación de las edificaciones a la regeneración de la ciudad existente. Claves de la evolución», Revista de Urbanismo y Edificación, núm. 24, 2011, pp. 41-60.; y del mismo autor (dir.), CASARES MARCOS, AB (coord.). Urbanismos sostenible, Rehabilitación, regeneración y renovación urbanas, Tirant lo Blanch, 2016; PONCE SOLÉ, J., «Políticas públicas para afrontar la regeneración urbana de barrios degradados. Una visión integrada desde el derecho", en Revista Aragonesa de Administración Pública, núm. 41-42, 2013, pp. 11-70.

(14) Vid. HERVÁS MÁS, J., op. cit., pp. 56-61. 
Este término de regeneración urbana ha sido incluido recientemente en nuestra normativa, sin perjuicio de las referencias a renovación y rehabilitación urbana recogidas en el Texto Refundido de la Ley del Suelo de 1992 o las señaladas en el art. 110 de la Ley 2/2011, de 4 de marzo, de Economía Sostenible, el término como tal no lo encontramos hasta el art. 17 del RD-Ley 8/2011, de 1 de julio, de medidas de apoyo a los deudores hipotecarios, de control del gasto público y cancelación de deudas con empresas y autónomos contraídas por las entidades locales, de fomento de la actividad empresarial e impulso de la rehabilitación y de simplificación administrativa, en la que se señala que el término rehabilitación engloba también al de regeneración urbana(15). La plasmación definitiva en una Ley estatal la encontramos en la Ley $8 / 2013$, de 26 de junio de rehabilitación, regeneración y renovación urbana, y posteriormente en el Texto Refundido aprobado por RD Legislativo $7 / 2015$, de 30 de octubre, por el que se aprueba el texto refundido de la Ley del Suelo y Rehabilitación Urbana.

Se contempla la regeneración urbana junto a la renovación, haciendo referencia a las actuaciones que afecten tanto a edificios como al tejido urbano, pudiendo llegar a incluir obras de nueva edificación en sustitución de edificios previamente demolidos. Teniendo el carácter integrador cuando articulen medidas sociales, ambientales y económicas enmarcadas en una estrategia administrativa global y unitaria (art. 2.1 TRLSyRU). Es decir, la regeneración va unida no sólo a actuaciones concretas sobre los inmuebles, sino que tiene un carácter aglutinador al englobar también actuaciones sobre el medio ambiente, social y económico en armonía con el principio de desarrollo sostenible.

Por consiguiente, las actuaciones sobre suelo urbano tienen por objeto:

-Rehabilitación edificatoria, cuando existan situaciones de insuficiencia o degradación de los requisitos básicos de funcionalidad, seguridad y rehabilitación de las edificaciones.

- Regeneración y renovación cuando afecten tanto a edificios como a núcleos urbanos.

- Obras de nueva edificación en sustitución de edificios previamente demolidos.

- Actuaciones de renovación urbana que implican demolición, sustitución y realojos.

(15) El art. 17 RDLey 8/2011 señala que la regeneración urbana comprende las actuaciones en "las que se desarrollen en ámbitos urbanos vulnerables, obsoletos o degradados, alcanzando tanto a la urbanización y a las dotaciones, como a los edificios, y tengan por finalidad el cumplimiento de los principios de cohesión territorial y social, eficiencia energética y complejidad funcional al servicio de un medio urbano sostenible.... . Tendrán carácter integrado cuando articulen medidas sociales, ambientales y económicas enmarcadas en una estrategia municipal global y unitaria, formulada a través del planeamiento urbanístico o por medio de un instrumento específico». 
Para que sea posible dicha regeneración global y unitaria es necesario que los ayuntamientos tengan un papel destacable en todo este proceso a través de las diferentes actuaciones plasmadas en las ordenanzas municipales que se desarrollan a nivel local(16). Será la administración local la que decida la mejor forma de actuar para acometer las actuaciones sobre suelo urbano de conformidad con la legislación aplicable por lo que deberán tener en cuenta la normativa autonómica.

Los legisladores autonómicos deberán configurar un marco normativo sobre la regeneración urbana al contar con competencia en materia de ordenación del territorio, urbanismo y vivienda(17), sin embargo, no ha tenido el recorrido que se pretendía ya que una parte considerable de la normativa no se ha reformado todavía de conformidad a la legislación estatal, y aquella que se ha adaptado parece haberse centrado especialmente, en la mayoría de los casos, en aquellos problemas que presentan los barrios degradados(18), dejando el resto de las actuaciones a la normativa nacional.

Entre la normativa autonómica (19) podemos destacar Ley $7 / 2014$, de 12 de septiembre, de medidas sobre rehabilitación, regeneración y re-

(16) Vid. sobre la importancia de los municipios en el proceso de regeneración urbana: ARROYOYANES, L.M., «El papel de la administración local en el impulso y fomento de la rehabilitación, la regeneración y la renovación urbana», en Quintana Lopez, T. (dir): Urbanismo sostenible. Rehabilitación, regeneración y renovación urbanas. Tirant lo Blanch, 2016, pp. 109-172.

(17) Se han planteado por parte de las Comunidades Autónomas diferentes recursos de inconstitucionalidad respecto a las leyes estatales urbanísticas por considerar que invadían su ámbito competencial, en este sentido respecto la LRRRU el País Vasco resolvió el conflicto en lugar de con un recurso de inconstitucionalidad con un Acuerdo por la Comisión Bilateral de Cooperación de la Administración del Estado-Administración de la Comunidad Autónoma del País Vasco en relación a dicha ley, solucionándose en los siguientes términos el posible conflicto (BOPV núm. 68, de 8 de abril de 2014) :

- Informe de Evaluación de Edificios que podría ser sustituido por el que tuviera previsto la normativa autonómica o municipal.

- Las actuaciones sobre el medio urbano no alteran las competencias, sino que se condicionan a razones de oportunidad

- Respecto a la memoria de viabilidad económica, el desarrollo de los medios para garantizar la efectividad ha de corresponder a la legislación autonómica.

Vid. sobre el conflicto de competencias entre el Estado y las Comunidades Autónomas ROZADOS OLIVA, MJ., "Las competencias el Estado y las Comunidades Autónomas en la Rehabilitación, Regeneración y Renovación urbanas», en QUINTANA LÓPEZ,T (dir.) y CASARES MARCOS, A.B. (coord.), Urbanismo sostenible. Rehabilitación, regeneración y renovación urbana. Tirant lo Blanch, 2016, pp. 71-107; así como GONZÁLEZ BUSTOS, M. a Á., "Distribucción y conflicto de competencias», en QUINTANA LÓPEZ, T (dir.), CASARES MARCOS, AB. (coord.), Derechos Urbanístico. Tirant lo Blanch, 2 ed., 2015, pp. 15-50; ...

(18) Vid. Tejedor Bielsa, J., Rehabilitación y regeneración urbana en España. Situación actual y perspectivas, Monografías de la Revista Aragonesa de Administración Pública XV, 2013; BRUQUETAS, M., MORENO, FJ y WALLISER, A., La regeneración de barrios desfavorecidos, Madrid, Fundación Alternativas, 2005..

(19) Normativa autonómica: Ley Catalana 2/2004, de 4 de junio, de mejora de barrios, áreas urbanas y villas; Ley 16/2010, de 21 de diciembre, de actuación integral en zonas de atención especial de 
novación urbana, y sobre sostenibilidad, coordinación y simplificación en materia de urbanismo de Castilla-León, que modifica la Ley 5/1999, de 8 de abril, de Urbanismo de Castilla y León, que contempla fundamentalmente la intervención y revitalización de los barrios históricos acogiendo como criterio general la rehabilitación, pero dando un margen para la demolición o sustitución(20). Las diferentes actuaciones de rehabilitación, regeneración y renovación urbana se planifican mediante diferentes instrumentos urbanísticos como el planeamiento general o mediante un plan especial de reforma interior (art. 156) dando prioridad a las actuaciones de rehabilitación frente a la sustitución, y abordaran entre otros objetivos la mejora de la eficiencia energética de los edificios, la supresión de barreras arquitectónicas, la adecuación de espacios públicos, edificios y viviendas a las necesidades de las personas mayores o discapacitadas, la recuperación de los valores urbanísticos, arquitectónicos y paisajísticos de los espacios urbanos, la mejora de los espacios libres, ....

La Ley 2/2006, de 30 de junio, de Suelo y Urbanismo del País Vasco, no dedica un apartado específico a la regeneración urbana pero si a la rehabilitación de construcciones, instalaciones y edificaciones (art. 2.1.c), y al principio de desarrollo sostenible (art. 3) señalando que la ordenación urbanística asumirá, como criterios orientadores, los principios del desarrollo urbano entre los que se destaca:...c) La ocupación sostenible del suelo, que contemple su rehabilitación y reutilización,...d) La construcción sostenible mediante la rehabilitación, dando prioridad a la regeneración del patrimonio construido y urbanizado en los núcleos originarios de la localidad y a la utilización de las viviendas vacías. En cambio, la Ley 3/2015, de 18 de junio, de vivienda del País Vasco, define la regeneración urbana como el proceso de intervención pública que integra los aspectos relacionados con el medio ambiente y las condicio-

\footnotetext{
la Comunidad Autónoma de Extremadura; Ley 3/2009, de 17 de junio, de urbanismo de Aragón; Ley 7/2000, de 19 de junio, de rehabilitación de espacios urbanos degradaos y de inmuebles que deban ser objeto de preservación; Ley 2/2009, de 19 de marzo, de rehabilitación y mejora de barrios de los municipios de las Illes Balears; Decreto 189/2009, de 23 de octubre, del Consell por el que se aprueba el Reglamento de Rehabilitación de edificios y viviendas de la Comunidad Valenciana; Decreto Foral Legislativo 1/2017, de 26 de julio, por el que se aprueba el Texto Refundido de la Ley Foral de ordenación del Territorio y Urbanismo que deroga entre otras leyes la Ley Foral 5/2015.de 5 de marzo, de medidas para favorecer el urbanismo sostenible, la renovación urbana y accesibilidad urbanística en Navarra;...

Respecto al análisis de la normativa autonómica en relación con la intervención de la misma en la regeneración de los barrios: HERVÁS MÁS, J.: Nuevo régimen jurídico de la regeneración urbana. Thomson Reuters Aranzadi, 2017, pp. 65-102
}

(20) Es de destacar en la gestión las reglas especiales para la gestión de actos de rehabilitación, regeneración y renovación urbana contemplados en el art. 157 sobre expropiación y ejecución subsidiaria o las que permiten que no se generen nuevas obligaciones a causa de los aumentos de edificabilidad volumen o densidad derivados de la sustitución de infraviviendas o las obras de mejora energética ... 
nes físicas, urbanas, sociales y económicas; y plantea alternativas para mejorar la calidad de vida de la población y las condiciones de la edificación, urbanización y dotaciones de un conjunto urbano o núcleo de población (art. 3.0).

En general, la mayoría de las leyes autonómicas no contemplan la regeneración urbana como uno de los elementos esenciales en el proceso de modernización de nuestras ciudades por lo que es preciso modificar y adaptar la legislación autonómica a los nuevos parámetros prestando atención en el desarrollo de las diferentes técnicas urbanísticas necesarias para la regeneración urbana de conformidad con la legalidad aplicable. Esto último es lo que ha llevado a cabo la Ley $3 / 2015$, antes mencionada, que contempla tal posibilidad en los art. 40 y siguientes, señalando entre otras las siguientes técnicas urbanísticas: declaración de necesidad de rehabilitación, planificación de la rehabilitación y regeneración urbana, acciones en el patrimonio edificatorio existente de rehabilitación y de mejora de las condiciones de habitabilidad y accesibilidad, gestión de la rehabilitación y regeneración urbana a través de los sistemas de actuación...

\section{Actuaciones a desarrollar para la regeneración urbana}

De conformidad con el art. 4.5 TRLSyRU: Las Administraciones Públicas adoptarán medidas que aseguren la realización de las obras de conservación, y la ejecución de actuaciones de rehabilitación edificatoria, de regeneración y renovación urbanas que sean precisas y, en su caso, formularán y ejecutarán los instrumentos que las establezcan, cuando existan situaciones de insuficiencia o degradación de los requisitos básicos de funcionalidad, seguridad y habitabilidad de las edificaciones; obsolescencia o vulnerabilidad de barrios, de ámbitos, o de conjuntos urbanos homogéneos; o situaciones graves de pobreza energética. Serán prioritarias, en tales casos, las medidas que procedan para eliminar situaciones de infravivienda, para garantizar la seguridad, salubridad, habitabilidad y accesibilidad universal y un uso racional de la energía, así como aquellas que, con tales objetivos, partan bien de la iniciativa de los propios particulares incluidos en el ámbito, bien de una amplia participación de los mismos en ella. Por consiguiente, son las Administraciones Públicas las que tienen que señalar las actuaciones necesarias para llevar a cabo la regeneración urbana priorizando las situaciones que necesitan ser intervenidas con mayor urgencia.

Entre las actuaciones concretas que se han puesto en marcha para un futuro inmediato podemos destacar: 


\section{Actuaciones sobre eficiencia energética en la edificación(21)}

Las políticas de la Unión Europea sobre regeneración urbana parten de actuaciones concretas sobre eficiencia energética, en este sentido la Directiva 2010/31/UE, del Parlamento y del Consejo de 19 de mayo de 2010, sobre eficiencia energética en los edificios, tiene como objetivo reducir el uso de energía en un $20 \%$ para el año 2020, y parte de la necesidad de adoptar acciones concretas con el fin de aprovechar el gran potencial de ahorro de energía de los edificios, ya que el $40 \%$ del consumo total de energía de la Unión Europea procede del sector de la edificación. Por consiguiente, se establece que a partir del 2020 los inmuebles que se construyan, así como la rehabilitación de los existentes deben englobarse en la categoría de edificios de consumo energético casi nulo.

En España existen más de 25 millones de viviendas construidas sin criterios de eficiencia energética para paliar tal situación se han elaborado planes nacionales de actuación como el 2. ${ }^{\circ}$ Plan de Acción de la Energía de Ahorro y Eficiencia Energética para el periodo 2011-2020; o el Plan Estatal Integral de Vivienda y Suelo de 5 de abril de 2013 que se ha plasmado en el Plan Estatal de Fomento de alquiler de viviendas, la rehabilitación edificatoria, y regeneración y renovación urbana 2013-2016 aprobado por RD 233/2013, y prorrogado por un año más por el RD 637/2016, de 9 de diciembre, con el objetivo de mejorar la calidad de la eficiencia energética de los edificios a través de programas que incidan sobre el fomento de la rehabilitación edificatoria, el apoyo a la implantación del informe de evaluación de los edificios y el fomento de ciudades sostenibles y competitivas. Este plan se complementa con la Estrategia a largo plazo para la rehabilitación energética en el sector de la edificación en España en coordinación con el Plan Nacional de Acción energética 2014-2020.

Respecto a la regulación de carácter general aprobada por el Estado la encontramos en la Ley 38/1999, de 5 de noviembre, de Ordenación de la Edificación, modificada por la Ley 8/2013, de 26 de junio, de Rehabilitación, Regeneración y Renovación Urbana(22), y derogada por el Texto Refundido de la Ley del Suelo y Rehabilitación Urbana (RDL 7/2015), que incide en la rehabilitación de los edificios por razones de eficientica energética y en la certificación de eficiencia energética en la edificación. El contenido específico de los criterios que deben tenerse en cuenta a la

(21) Vid. GONZÁLEZ BUSTOS, M. ${ }^{a}$ A., "Marco jurídico y actuaciones administrativas sobre la eficiencia energética de los edificios", en Revista de Derecho Urbanístico y Medio Ambiente, número 316, 2017, pp. 141-178.

(22) Vid. FERNÁNDEZ TORRES, J.R., "La rehabilitación, regeneración y renovación urbana: contexto y desafíos a propósito de la Ley 8/2013, de 26 de junio", en RDU núm. 40, 2014, pp. 15-38. 
hora de rehabilitar una edificación se desarrollan en el Código Técnico de la Edificación (RD 314/2006, de 17 de marzo,) que se ha ido adoptando a la nueva normativa(23), así como el Reglamento de Instalaciones Térmicas en los Edificios (RD 1027/2007, de 20 de julio, modificado por RD 238/2013, de 5 de abril).

Entre las medidas que se han adoptado en la edificación se ha de señalar el certificado de eficiencia energética, el informe de Evaluación de Edificios, líneas de financiación a través de incentivos, ... Pero donde realmente hay que incidir es en la rehabilitación, y por lo tanto regeneración de los espacios urbanos, para conseguir que en el 2020 todos los edificios sean edificios de consumo casi nulo ya que en más del $53 \%$ de viviendas son anteriores a la entrada en vigor de la primera normativa sobre aislamiento de 1979. Rehabilitar un edificio supone un ahorro energético y de contaminación del $60 \%$ aproximadamente frente a la construcción de otro nuevo ya que el coste energético de fabricación es muy elevado unido a otros costes económicos y sociales como los derivados de un desalojo y realojo temporal de los propietarios actuales de los inmuebles.

La necesidad de avanzar en la elaboración de una normativa adecuada que contemple la rehabilitación de edificios es fundamental para conseguir la regeneración de la ciudad que tiene que tener en cuenta diferentes factores como son los económicos, la información a los consumidores para concienciar a los mismos de la necesidad de la rehabilitación de sus viviendas, la protección del patrimonio histórico-artístico, las leyes urbanísticas... (24)

\section{Regeneración de barrios o núcleos de población que necesitan de una inmediata intervención}

La degradación urbana de muchos barrios debido al no cumplimiento del deber de conservación por parte de sus propietarios o la dejadez por

(23) El Código Técnico de la Edificación tiene por objeto la mejora de la calidad de la edificación y la promoción de la innovación y sostenibilidad. Según su exposición de motivos "se trata de un instrumento normativo que fija las exigencias básicas de calidad de los edificios y sus instalaciones", estableciendo los requisitos básicos de las nuevas edificaciones, así como las intervenciones que se acometan en los edificios existentes, relacionados con la seguridad y el bienestar de las personas que hacen referencia tanto a la seguridad estructural y de protección contra incendios como a la salubridad, la protección contra el ruido, el ahorro energético o la accesibilidad para personas con movilidad reducida: Real Decreto 173/2010 de 19 de febrero, por el que se modifica el Código Técnico de la Edificación, aprobado por el Real Decreto 314/2006, de 17 de marzo, en materia de accesibilidad y no discriminación de las personas con discapacidad. (BOE 11-marzo-2010).

(24) Se aboga por la revisión de la Directiva de eficiencia energética de los edificios (también la de eficiencia energética) para establecer un marco normativo más adecuado, sobre todo teniendo en cuenta los avances de estos últimos años en el sector, para lo cual es necesario adoptar medidas complementarias de apoyo y el abordaje de la financiación tanto pública como privada. 
parte de muchos municipios, unido a asentamientos de colectivos en circunstancias más desfavorecidas ha llevado a situaciones que necesitan ser atajadas con celeridad, estableciendo actuaciones dirigidas a la mejora, conservación y rehabilitación de los edificios y espacios públicos a través de proyectos concretos de regeneración urbana.

Cobra especial importancia en este punto el fomento de las iniciativas regeneradoras por parte de las Administraciones Públicas que se pone de manifiesto a través de ayudas públicas, la mayoría de los casos por medio de subvenciones. En este sentido, la Administración General del Estado por medio del Planes Estatales de Viviendas, conceden ayudas para la rehabilitación, regeneración y renovación del medio urbano; que deberían ser complementadas por ayudas autonómicas y municipales o provinciales cuando la situación económica se lo permitiera.

Son de destacar las ayudas y financiaciones procedentes de la Unión Europea como son los proyectos concretos de regeneración urbana de barrios o núcleos de población, a través de programas comunitarios como los Fondos FEDER(25).

Entre dichos proyectos podemos señalar el proyecto de Pasai (Pasajes) con un importe de 21 millones de euros, en el que en la bahía de Pasaia situada dentro del Área metropolitana de Donostia (San Sebastian) se integrara el Puerto en la ciudad con el objeto de mejorar la calidad ambiental y urbana, y a su vez mejorar el nivel económico de la zona. Las mejoras que se han realizado han convertido el espacio en un "puerto urbano».

$\mathrm{O}$ el proyecto de reactivación del casco medieval de Vitoria (Gasteiz) que ocupa la zona central de la ciudad, y que es una ubicación con gran valor turístico por lo que se pretende mejorar la accesibilidad del mismo, y para ello se incorporó la instalación de rampas mecánicas y ascensores, diseño de itinerarios peatonales, mejora la señalética, además de la rehabilitación y adecuación de los locales y edificios junto con la creación de una residencia de estudiantes.

Dentro del Programa Horizonte 2020 se han creado nuevas estrategias de desarrollo urbano sostenible (EDUSI) como el Eje Urbano dentro del Programa Operativo de Crecimiento Sostenible (POCS) 2014-2020 dedicado en su totalidad a financiar líneas de actuación de Desarrollo Urbano Sostenible e Integrado. Este eje con una dotación de 1.012.754.015 € va dirigido a municipios o agrupaciones de municipios que constituyan un área funcional urbana, con población de más de 20.000 habitantes (26).

(25) Vid. HERVÁS MAS op. cit., pp. 157-281 donde se describen todas las iniciativas de regeneración urbana financiadas a cargo de los fondos FEDER de la Unión Europea.

(26) Existe un proceso de convocatoria debiendo cumplir unos requisitos y concretamente el total de ayudas concedidas para el País Vasco asciende a 9.282.000€ concedida al Ayuntamiento de Bilbao para la regeneración Zorrotzaurre. 


\section{La planificación urbanística}

La regeneración de espacios urbanos, así como del parque inmobiliario, hace necesario la utilización de instrumentos concretos como la planificación urbanística, de esta forma los planes urbanísticos se configuran como instrumentos idóneos para acometer la regeneración de una zona urbana determinada (27). Dentro de los mismos son de destacar los planes de reforma interior que son aquellos planes especiales de ámbito municipal que ordenan sectorialmente el territorio cuyo objetivo es la renovación del suelo urbano estableciendo, completando o modificando la ordenación urbana existente para modernizar y mejorar las condiciones de vida en el medio urbano. Entre los objetivos específicos del mismos podemos señalar: descongestión de las ciudades, creación de dotaciones urbanísticas y equipamientos comunitarios, saneamiento de barrios insalubres, resolución de problemas de circulación o de estética, mejora del medio ambiente o de los servicios públi$\cos . . .(28)$.

En concreto se pueden señalar las siguientes finalidades de los planes de reforma interior (29):

- Acometer operaciones de renovación urbana tendentes a mejorar densidades determinadas por un determinado número de viviendas por hectárea.

- Reequipar barrios enteros, es decir dotar de nuevas dotaciones urbanísticas de las que se adolece, o estas, en caso de existir se encuentren en mal estado.

(27) Vid., entre otras, la STS 8 de marzo de 2010 que señala que los planes parciales no ordenan el territorio desde una perspectiva integral y global, sino que atiende a un sector concreto y determinado. $Y$ en general sobre los instrumentos urbanísticos para la regeneración: FERNÁNDEZ ACEVEDO, R., «Instrumentos y técnicas urbanísticas para la rehabilitación, regeneración y renovación urbana», en QUINTANA LÓPEZ,T (dir.), Urbanismo Sostenible. Rehabilitación, regeneración y renovación urbanas. Tirant Lo Blanch, 2016, pp. 173-216; MENÉNDEZ REXACH, A., "Instrumentos jurídicos para la regeneración urbana», en Revista de Derecho Urbanístico y Medio Ambiente, 2011, núm. 270, pp. 13-49; TEJEDOR BIELSA, J., «Planes, programas y otros instrumentos ordenadores de la Rehabilitación Urbana», en Práctica Urbanística, en Revista de Urbanismo, 2015, núm 133, pp. 70-81;...Así como la Ley de Urbanismo de Castilla y León 5/1999, de 8 de abril, modificada por la Ley 7/2014, de 12 de septiembre, de medidas sobre rehabilitación, regeneración y renovación urbana, y sobre sostenibilidad, coordinación y simplificación de urbanismo en Castilla y León (art. 156 y 157).

(28) Vid. LAFUENTES BONACHES, M., "Los Planes Especiales de Reforma Interior", en Revista de Derecho urbanístico y Medio Ambiente, núm. 114, p. 39. En este sentido la STSJ de Murcia de 29 de mayo de 2015 señala que los planes de reforma interior y rehabilitación tienen un ámbito territorial específico y se trata de un suelo urbano que necesita esa reforma o rehabilitación, es decir, la mejora de los aspectos concretos mediante la creación de nuevas dotaciones o bien resolviendo problemas de accesibilidad, comunicaciones, saneamiento de barrios, etc.

(29) Vid. Sobre los planes de reforma interior HERVÁS MÁS, J.: Nuevo régimen jurídico de la regeneración urbana. Thomson Reuters Aranzadi, 2017, pp. 291-337. 
- Modernizar el destino urbanístico de barrios enteros preservando el patrimonio arquitectónico de interés por medio de la rehabilitación del barrio.

Por lo que los Planes de Reforma Interior se configuran para dar soluciones a situaciones que no están contempladas en los Planes Generales o que necesitan ser reformadas o adaptadas al momento actual, modernizando la ciudad y conservando lo que tenga un valor cultural, histórico o urbano.

El legislador autonómico es el encargado de desarrollar dichos planes señalando su objeto (operaciones de reforma interior o reordenación urbana, rehabilitación de zonas degradas y saneamiento de barrios insalubres, rehabilitación de inmuebles, creación de dotaciones urbanísticas y equipamientos comunitarios, solución de problemas de circulación...), ámbito de actuación (suelo urbano consolidado o no consolidado por la urbanización), modalidades de gestión...

En esta línea han comenzado a trabajar las diferentes Comunidades Autónomas, como se manifiesta mediante la Ley Foral 35/2002, de 20 de diciembre, de Ordenación del Territorio y Urbanismo de Navarra, modificada por la Ley Foral 5/2014, de medidas para favorecer el Urbanismos Sostenible, la renovación urbana y la actividad urbanística de Navarra, y recientemente derogada por el Decreto Foral Legislativo 1/2017, de 6 de julio, por el que se aprueba el Texto Refundido de la Ley Foral de Ordenación del Territorio y Urbanismo, que señala como instrumentos de planificación específica para la rehabilitación, regeneración y renovación urbana el Plan Especial de Actuación Urbana (art. 62) teniendo por objeto desarrollar sobre cualquier clase o categoría de suelo las determinaciones de la ordenación estructurante contenidas en los Planes Generales Municipales, así como establecer, modificar o completar su ordenación pormenorizada (art. 61).

O la Ley 2/2006, de 30 de junio, del Suelo y Urbanismo del País Vasco, que diferencia entre Planes Especiales de Ordenación Urbana y Planes Especiales de Renovación Urbana. Los primeros tienen por objeto desarrollar la ordenación estructural del plan general mediante el establecimiento de la ordenación pormenorizada de aquellas áreas de suelo urbano para las que el plan general permite diferir dicha ordenación (art. 70); y los planes especiales de renovación urbana que tendrán por objeto el desarrollo de actuaciones concretas que, conservando la estructura fundamental y sin alterar la edificabilidad urbanística, tengan por finalidad descongestionar el suelo urbano, la creación de dotaciones públicas y equipamientos colectivos privados, el saneamiento de barrios, la regeneración y rehabilitación urbana, la reforma interior , a la resolución de problemas de movilidad o estética, mejora del medio ambiente o de los servicios públicos... (art. 71). 
Al amparo de estos Planes las provincias de Álava, Vizcaya y Guipuzcoa han recurrido a los Planes de Reforma Interior aprobados y en tramitación, por ejemplo en San Sebastián, el Plan Especial de Ordenación Urbana del Área Interior de Txomin Enea, en Vitoria-Gasteiz y Bilbao se han centrado más en el Casco histórico.

Las actuaciones de regeneración urbana exigen que los instrumentos de planeamiento a tener en cuenta sean los Planes Especiales (de Reforma Interior, Reforma Urbana o Actuación Urbana(30)) que llevan incluidos en muchos casos cambios de usos globales, incrementos de la edificabilidad o actuaciones de densidad edificatoria. Teniendo en cuenta que en el caso de que impliquen la necesidad de alterar la ordenación urbanística vigente deberán observar los trámites procedimentales requeridos por la legislación aplicable para realizar la correspondiente modificación. No obstante, tal legislación podrá prever que determinados programas u otros instrumentos de ordenación se aprueben de forma simultánea a aquella modificación, o independientemente de ella, por los procedimientos de aprobación de las normas reglamentarias, con los mismos efectos que tendrían los propios planes de ordenación urbanística. (art. 24.1 TRLSyRU).

La Administración Local es la principal encargada de hacer cumplir los planes especiales para lo cual necesita ayudas no sólo económicas sino de diferentes entes y un papel destacable lo tienen las sociedades municipales de rehabilitación que se utiliza fundamentalmente en el País Vasco, para que las entidades locales al constituir este tipo de sociedades puedan cumplir con las determinaciones de los planes especiales de rehabilitación (31).

Además de la planificación y unido a la misma se puede hacer mención, como instrumento adecuado para la regeneración urbana, a los estándares urbanísticos definidos como una técnica de reducción de la discrecionalidad propia de la potestad de planeamiento a través de la fijación de unas reglas de fondo que actúan como límites legales a aquella potestad (32).

Por cuanto al suelo urbano se refiere estos estándares, además de la edificabilidad y de dotaciones que con carácter general se exigen, tienen que tener en cuenta otros indicadores como la calidad urbana, la calidad de la ordenación de espacios públicos resultantes y las condiciones funcionales de accesibilidad y uso de las dotaciones públicas (33).

(30) La denominación depende de la legislación autonómica.

(31) Vid. ARROYOYANES, LM., «El papel de la administración local..., pp. 167-168.

(32) GARCÍA DE ENTERRÍA, E. y PAREJO ALFONSO, L., Lecciones de Derecho urbanístico. Civitas, 1981, p. 76.

(33) Vid. Sobre los estándares urbanísticos aplicables a la regeneración urbana: HERVÁS MÁS, J., op. cit., pp. 328-337. 
Las normas autonómicas remiten el cumplimiento de estos estándares a las reglas establecidas en los Planes Parciales, por lo tanto, es el Plan de Reforma Interior el que establecerá los mismos de forma motivada teniendo en cuenta la situación de consolidación existente y plantear una relación adecuada entre los estándares dotaciones y los estándares de edificabilidad (34).

\section{Conclusiones}

Cuando se habla de regeneración urbana no sólo debemos abordar la rehabilitación o renovación de los cascos históricos de las ciudades, de los barrios periféricos, de los edificios sino que es fundamental partir de la protección de las áreas colindantes es decir del medio natural (espacios protegidos, atmósfera, flora y la fauna....), lo que supondrá realmente una regeneración integral pues sólo así conseguiremos un desarrollo sostenible eficiente y de calidad. Por lo tanto, la sostenibilidad va unida a la mejora del medio ambiente aplicando criterios de eficiencia energética para reducir el impacto ecológico y la subsistencia de nuestro planeta.

Las actuaciones a realizar para la regeneración de un área urbana se pueden resumir en las siguientes:

- Renovación de los barrios periféricos y degradados, la mayoría de ellos marginales que no cuentan con ningún valor histórico o artístico que justifiquen su mantenimiento. Existen dos soluciones factibles, pero sólo una es operativa: la primera que sería la que se descartaría ya que supondrían unos costes muy elevados y que sería la devolución de esos terrenos al medio natural; y la segunda será la demolición y reconstrucción de las zonas más degradadas y la rehabilitación del resto, basada en criterios de sostenibilidad. Para llevar a cabo esta actuación se necesita de la labor exhaustiva del planificador y del gestor que establezca las líneas de acción adecuadas.

- La rehabilitación de edificios con criterios de eficiencia energética para producir un menor consumo de energía y una menor contaminación.

- Aumento de la calidad y seguridad del entorno urbano retornando a valores globales de colectividad que tan arraigados estaban hace unos años en los espacios públicos (calles, parques y jardines, plazas...) para lograr una mayor protección y seguridad de los ciuda-

(34) Los estándares den Suelo Urbano del País Vasco se encuentran contemplados en el Decreto 123/2012, de 3 de julio, señalando en el art. 6 los estándares mínimos para reserva de terrenos destinados a dotaciones y equipamientos de la red de sistemas locales en suelo urbano no consolidado de actuaciones integradas y de dotación por incremento de edificabilidad. 
danos evitando la formación de guetos que provocan inseguridad en dichos espacios públicos.

Pero el mayor problema al que se enfrenta la regeneración urbana es que se está centrando en el medio urbano de las grandes ciudades la mayoría de más de 20.000 habitantes, pero que pasa con los demás núcleos urbanos en los que los ayuntamientos no cuentan con presupuesto necesarios para los servicios esenciales como la educación, o la sanidad, o incluso para el alumbrado o la recogida de basura, por no mencionar el transporte. En todas estas áreas nos encontramos con graves problemas de funcionamiento de las infraestructuras por lo que es necesario adoptar medidas urgentes que afronten esas situaciones, y eviten en muchas ocasiones la despoblación de esas zonas, para que la llamada regeneración urbana sea una realidad en toda la sociedad y no sólo en parte de ella (35).

El legislador ha establecido un marco normativo idóneo para la regeneración urbana lo que va a permitir una reconversión y activación del sector de la construcción con nuevos ámbitos de actuación, así como el fomento de la calidad, sostenibilidad y competitividad de la edificación y del suelo cumpliendo con los objetivos de eficiencia, ahorro energético y lucha contra la pobreza energética (36). Los poderes públicos han de incidir sobre este aspecto, que sin perjuicio de que han puesto muchos instrumentos a nuestro alcance para conseguirlo, sin embargo, existe otra gran dificultad con la que se encuentran los diferentes gobiernos que no es otra que la concienciación y la educación de las personas la cual resulta esencial para lograr un medio urbano adecuado a sus necesidades presentes y futuras.

(35) En la misma línea FARIÑA TOJO, J., "Ciudad sostenible, rehabilitación arquitectónica y regeneración urbana", en Monografías de la Revista Aragonesa de la Administración Pública, XV, 2013, pp. 15-26, en concreto pp. 24-26.

(36) Exposición de Motivos de la Ley de rehabilitación, regeneración y renovación urbana, de $8 / 2013$, de 26 de junio. 
LABURPENA: Hiri-garapenak beharrezko egiten du espazioa berroneratzeko arloko jarduera zehatzak abiaraztea, kontrolik gabeko garapenetik datozen arazo guztiak jorratu ahal izateko eta herritarrei bizi-kalitate egokia eman ahal izateko. Horretarako, ezinbestekoa da oinarri juridiko egokia edukitzea eta hainbat frontetan jardutea; adibidez, hauetan: auzoen edo biztanleguneen berroneratzean, eraikinen energia-eraginkortasunean edo hirigintza-plangintzan.

GAKO HITZAK: Hiri-berroneratzea. Garapen jasangarria. Lurzorua. Politika publikoak. Energia-eraginkortasuna. Eraikuntza. Hirigintza-plangintza.

RESUMEN: El desarrollo urbano hace necesario que se adopten actuaciones concretas en materia de regeneración del espacio para acometer todos los problemas derivados de un desarrollo incontrolado así como satisfacer una calidad de vida adecuada a los ciudadanos. Para lo cual es indispensable tener una base jurídica adecuada y actuar en diferentes frentes como es la regeneración de barrios o núcleos de población, la eficiencia energética de los edificios, o la planificación urbana.

PALABRAS CLAVE: Regeneración urbana. Desarrollo sostenible. Suelo. Políticas públicas. Eficiencia energética. Edificación. Planificación urbanística.

ABSTRACT: Urban development makes it necessary to adopt concrete actions in the matter of regeneration of space to tackle all the problems arising from uncontrolled development as well as to satisfy a quality of life adequate to the citizens. For this, it is essential to have an adequate legal base and to act on different fronts such as the regeneration of neighborhoods or population centers, the energy efficiency of buildings, or urban planning.

KEYWORDS: Urban regeneration. Sustainable development. Soil. Public policies. Energy efficiency. Building. Urban planning. 